\title{
Infarct topography and hemiparesis profiles with cerebral convexity infarction: the Stroke Data Bank
}

\author{
J P Mohr, M A Foulkes, A T Polis, D B Hier, C S Kase, T R Price, T K Tatemichi, \\ P A Wolf
}

\begin{abstract}
For the 183 of 1276 patients in the NINDS Stroke Data Bank with convexity infarction in the middle cerebral artery territo$r y$, the size of the infarct did not differ between the two sides but the location of the main site of the infarct differed: on the left side, it was centred in the inferior parietal region, and was mid-frontal on the right. There was a good correlation between infarct size and weakness severity whether estimated by overall motor function on one side, arm, or hand alone. There was a poor correlation, however, for lesion location (lower third, middle third or upper third on either side of the Rolandic fissure) and any of the specific syndromes of focal weakness, no two cases sharing the same lesion for the same syndrome and several cases sharing the same lesion with a different syndrome. The findings indicated a difference in weakness syndromes between the two hemispheres and great individual variation of the acute syndrome caused by a given site of focal infarction along the Rolandic convexity. These variations may explain some of the difficulties showing effects of a given therapeutic agent in studies of acute ischaemic stroke. Large sample sizes will be required for the reliable assessment of any treatment using currently popular clinical stroke scales.
\end{abstract}

\section{(尹 Neurol Neurosurg Psychiatry 1993;56:344-351)}

For more than a century, neurologists have based clinical diagnosis in stroke on the tacit assumption that the lesion caused by infarction is more or less the same in each of the two cerebral hemispheres and that there is a fairly reliable correlation between the clinical syndrome and the locus and size of the brain lesion. Of all the clinico-anatomical correlations, syndromes of weakness seemed the most reliable, using the attractive metaphor of an homunculus, ${ }^{1-3}$ with movements of the oropharynx, lips and tongue from activity of the low Rolandic region and insula, the face from the Rolandic cortex just above, the arm, hand and fingers even higher regions, and the leg, foot and genitalia from the Rolandic regions over the longitudinal fissure. Movements of the shoulder and hip may arise from motor areas just anterior to the Rolandic region. ${ }^{4}$ Those of the trunk and neck have not yet been adequately localised.

The importance of motor function in activities of daily living has made it a major element of clinical stroke scales. These scales range widely over the body parts tested, types of assessment of movements, and numerical values assigned. ${ }^{5-9}$ Any means of assessment of motor weakness has shown a robust interobserver reliability..$^{9-11}$ Scales for the rating of sensory function and aphasia have been given less emphasis, possibly because tests for these conditions are time consuming, more difficult to evaluate, and such disturbances are thought to be less important for functional status.

Because treatment for acute ischaemic stroke is now being carried out even before brain images have become positive, increasing reliance is being placed on early clinical assessment. ${ }^{12}$ One result has been to force clinical scales to bear the burden of assuming a direct correlation with brain lesions, which many were not originally designed to do. To determine whether such faith has been justified, we analysed the prospectively-collected data concerning motor syndromes and CT scan findings in the NINDS Stroke Data Bank. The analysis was limited to superficial convexity infarcts in the middle cerebral territory, because it was considered that this group would prove the most sensitive in showing clear correlations between brain lesions and motor weakness syndromes.

\section{Materials and methods}

The Stroke Data Bank (SDB) ${ }^{9}$ was a prospective observational study started as a pilot study from 1978-82. During the main phase of the study, from 1983-86, clinical and laboratory data were collected during the acute and follow-up phases in patients admitted to hospital for acute stroke in institutions where personal observations by the investigators were possible. This collaborative study involved the Biometry and Field Studies Branch of the NINDS as the statistical coordinating centre, and four academic centres: University Hospital of Boston University Medical Center, Michael Reese Hospital and Medical Center, University of Maryland Hospital, and the Neurological Institute of Columbia-Presbyterian Medical Center. Information was collected on each patient concerning the details of medical, neurological and social history, general and neurological examinations, laboratory studies, and final diagnosis, with special procedures for compli- 
cations, stroke evolution, stroke recurrence and death. The test used for brain imaging was the CT scan, as MRI scanning was not in general use during the period of data collection. At the time of hospital discharge, a diagnosis was determined taking into account all the available data.

Each patient with acute stroke was examined by one of the SDB investigators within a week of onset (initial clinical examination done at a median of 46 hours from onset) and most had initial and subsequent CT scanning (the initial CT scan done at a median of 20 hours from onset). Included in the large number of clinical examination elements were assessment of weakness of the face and tongue, estimated on a 3 point scale; the shoulder, wrist (hand), hip, and ankle (foot) were graded according to a commonly used 5 point scale. The total weakness score ranged from 0 (normal) to 30 for unilateral paralysis and as high as 60 for bilateral paralysis.

The investigators at each centre sketched the location and volume seen on the CT scan on a series of axial views on the SDB CT form created from the atlas published by Gado, Hanaway and Frank. ${ }^{13}$ The sketches were drawn in the appropriate anatomical location and relative size, taking into account any angulation of the head. Once the sketch was complete, a plastic transparency with a cartesian grid was placed over each section. Each specific grid element was then entered into the computer as a "vowel", capable of individual retrieval. In addition to storing the cartesian grid information, the computer treated each vowel as a brain volume; the average volume per grid element was 1.822 $\mathrm{ml}$. A program calculated the volumes for each grid element to give an estimate of the total lesion volume.

For the lateral convexity infarcts, the grid elements representing the surface of the convexity were selected by computer program and displayed on a specially created lateral view of the convexity using the same co-ordinates as those used in the Gado, Hanaway and Frank maps. The displays for the individual cases were then merged to create a composite picture for the right and left hemispheres. A three-dimensional grey scale was used to demonstrate the areas shared by given proportions of cases. To guard against misplotting the data of the few cases with high convexity lesions because of the possible effects of tilt of the head, ${ }^{14}$ we included all high convexity cases whose lesion lay within three voxels anterior or posterior to the Rolandic sulcus.

In those cases where more than one clinically-related convexity infarction was documented on CT, the clinical CT analyses were based on the first recorded lesion in the Data Bank. The timing of the scans for the onset of the stroke were recorded. As up to $20 \%$ of CT findings may be from clinically silent stroke, ${ }^{15}$ the studies were limited to those positive CT scans considered to be symptomatically related to the syndrome.

From the cohort of eligible cases, sub- groupings were made comprising those with a stable clinical course without changes in the neurological examinations, and those whose CT scan abnormality crossed the Rolandic sulcus. In retrieving the CT scan data for our study, the qualifying cases were limited to those whose infarcts affected the convexity and which spared structures of the corona radiata, internal capsule, basal ganglia, thalamus, brainstem and cerebellum.

\section{Results}

Among the 1806 cases of acute stroke in the NINDS Stroke Data Bank, 1483 were diagnosed as infarction but not classified as lacune and had detailed data on the first examination with complete CT scan data recorded. From this group 1273 were free of stroke recurrence during admission to hospital and the data were suitable for acute syndrome analysis. Complete information on the motor examination (no omissions or items filled in as "unknown" or not determined) on admission and at 7-10 days from the event was available for 1219 cases. Of these, 910 had their first CT scan done within 30 days of onset of the stroke. A total of 627 were available with complete motor examination data at one year. All 183 cases with CT positive infarction limited to the convexity were selected from this group and formed the basis for the study.

As expected, when the scan is used for acute stroke diagnosis, the first CT scans were done early after stroke, with many fewer as the days progressed. However, the mean size of the first positive CT scan showed little effect of the time it was performed after stroke. For the 12 patients with a stable clinical course who had two or more CT scans during admission to hospital, the relative change in CT lesion size was also quite small, and was too small to influence the main correlations.

The mean lesion size for the first positive CT scan did not differ between the two sides $(47 \cdot 7 \mathrm{cc}, 95 \%$ CI $39-56$ vs $41 \mathrm{cc}, 95 \% \mathrm{CI}$ $34-49, \mathrm{p}>0.32$ ). There was also no significant difference between the mean lesion size for the 183 cases of convexity infarction (mean lesion size $31.3 \mathrm{cc}, 95 \%$ CI 25-37) and for the 153 with a stable clinical course (30.4 cc, 95\% CI 24-37).

The composite lesion on the first positive CT scan centred in the peri-Rolandic region on each of the left and right hemispheral images, with less frequent involvement in contiguous regions spreading from the epicentre. The central focus shared by more than $50 \%$ of cases differed on the two sides. On the left, the lesion that was centred in the inferior parietal region, while on the rightsided cases it was centred in the mid-frontal region. The findings were essentially the same for the smaller subset with the stable clinical course (fig 1A, B).

Clinical and CT scan observations were available for the 153 cases whose clinical course was stable (there was no change in the 
Stable clinical course $(N=153)$ Left side
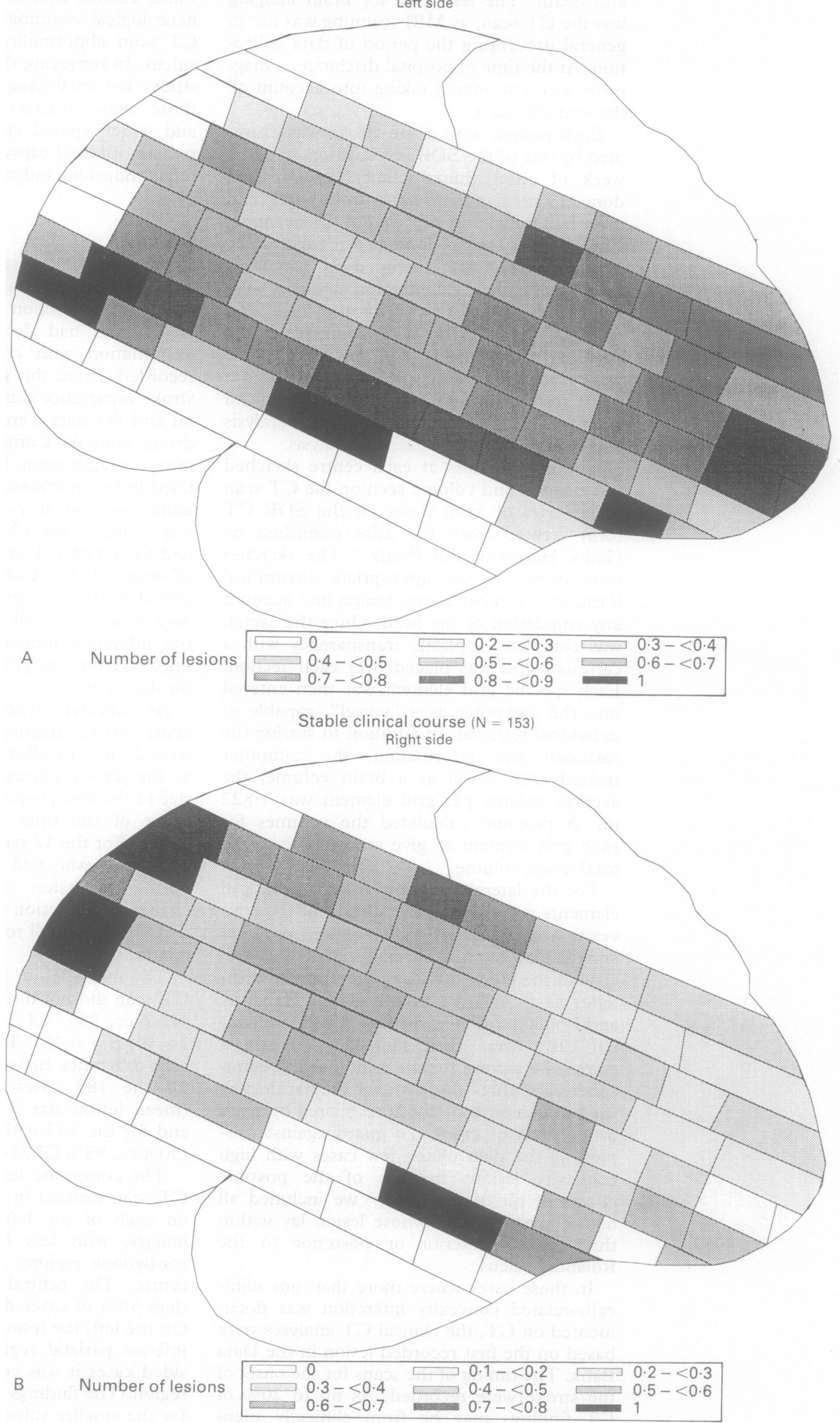

Figure 1 Lesion distribution for the left $(A)$ and right $(B)$ convexity in the 153 patients with a stable clinical course. The shading reflects the percentage of cases sharing the same lesion sites. 

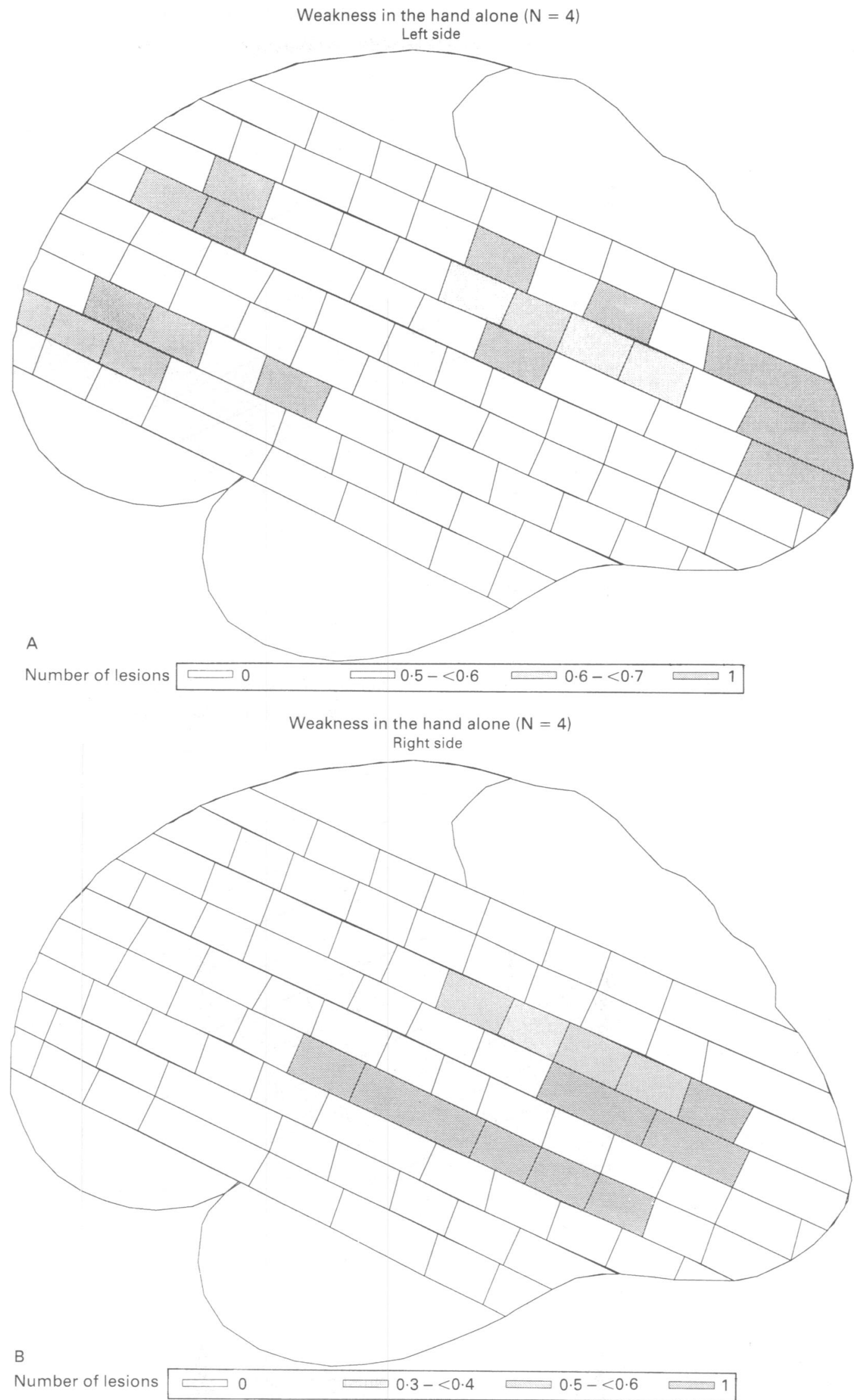

Figure 2 Lesion distribution for the left $(A)$ and right $(B)$ convexity in the patients with weakness confined to the hand. The shading reflects the number of cases sharing the same lesion sites. 


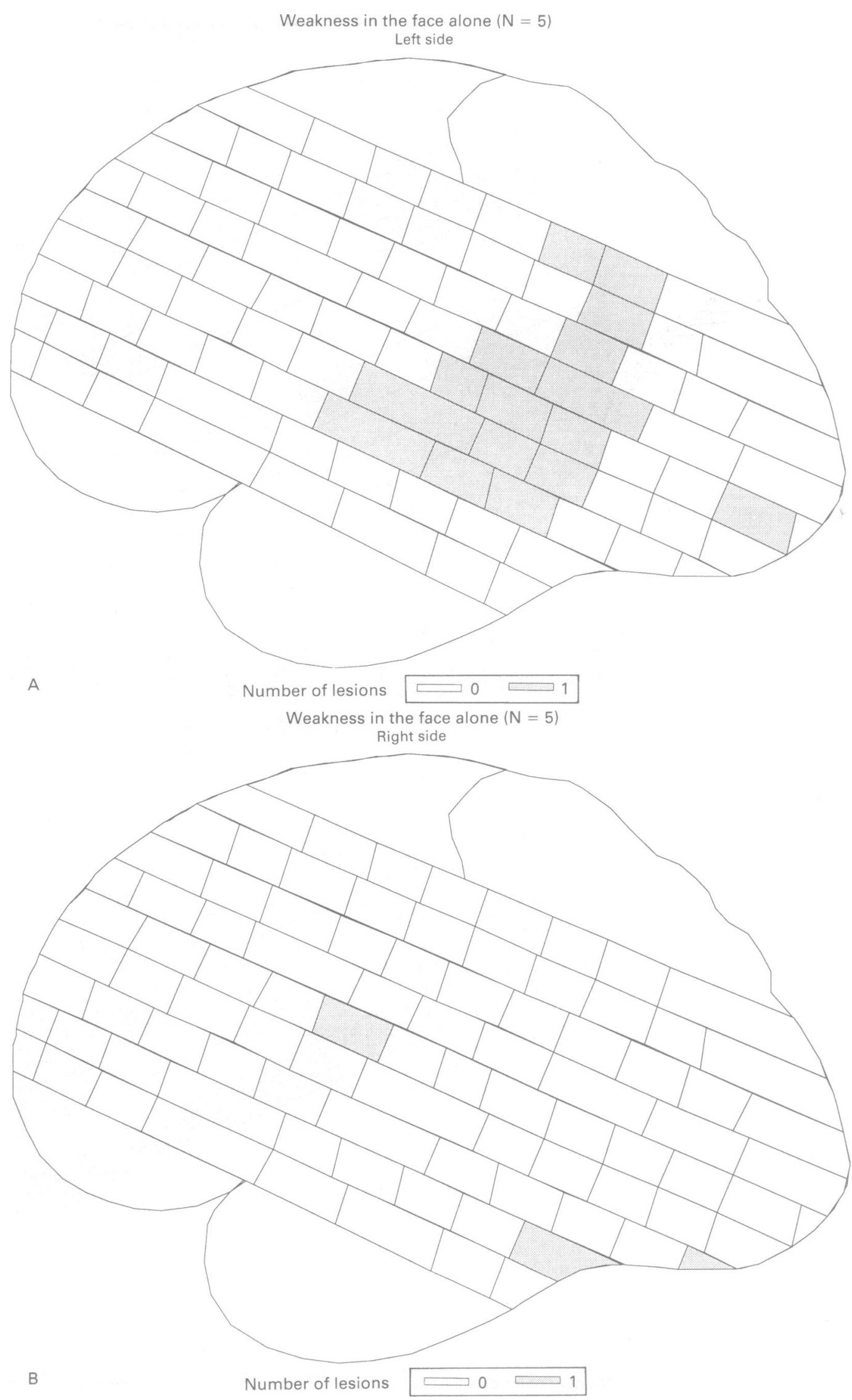

Figure 3 Lesion distribution for the left $(A)$ and right $(B)$ convexity in the patients with weakness confined to the face. The shading reflects the percentage of cases sharing the same lesion sites. 
neurological score between the admission examination another seven to 10 days later). $T$ tests for the difference in mean volume of infarction for each hemispheres were not significantly different for the first positive CT scan for those whose first examination showed any degree of hemiparesis ( $p>$ 0.47 ), nor for those with any degree of weakness in the arm as defined by combined scores for the shoulder and hand ( $p>0.42)$, nor for those with any degree of weakness in the leg defined by combined scores for the hip and ankle ( $p>0.41)$.

The vast majority of the 153 cases with a stable clinical course showed weakness affecting the face-arm-leg to varying degree. Only 18 of these cases had a positive scan and contralateral weakness involving the face-arm but not leg, or arm-leg but not face. The overlay of the plots showed several instances where a given site was associated with one motor profile in one case, and a different one in another. Only eight cases had weakness limited to the arm (shoulder and hand), each associated with a fairly small lesion, but the lesions were scattered on either side of the mid-Rolandic region, only two of which shared the same focus. Five other cases had weakness limited to the hand, each also associated with a single lesion. These were scattered around the Rolandic region (fig $2 \mathrm{a}, \mathrm{b}$ ). The five cases with isolated facial weakness also showed considerable variation in lesion location: on the left side the lesions were well behind the Rolandic region (fig 3a, b). Only one case had isolated weakness of the leg or foot with an infarct on the convex surface. In none of the 18 instances of incomplete hemiparesis were the lesions high enough over the convexity to have the plot of the main lesion site affected by unusual variations in the position of the head in the CT gantry.

Few examples were found of weakness limited to a single body part. In this latter group there was also a very wide variation in the lesion size for those with weakness confined to the face, to the hand or to the arm alone (table 1). An even larger variation in size was found for those lesions when the weakness syndrome affected one limb only when com-

Table 1 Lesion volume and monoparesis

\begin{tabular}{lrrr}
\hline & Number & Mean & \multicolumn{1}{l}{$95 \%$ CI } \\
\hline Convexity infarcts & 183 & $31 \cdot 33$ & $25 \cdot 37-37 \cdot 29$ \\
No worsening & 153 & $30 \cdot 46$ & $23 \cdot 74-37 \cdot 18$ \\
Arm weakness only & 4 & $27 \cdot 42$ & $9 \cdot 64-64 \cdot 48$ \\
Hand weakness only & 4 & $34 \cdot 51$ & $0 \cdot 26-69 \cdot 28$ \\
Face weakness only & 5 & $22 \cdot 30$ & $4 \cdot 52-40 \cdot 07$ \\
\hline
\end{tabular}

Table 2 Left-sided lesion volume and hemiparesis formula

\begin{tabular}{|c|c|c|c|}
\hline $\begin{array}{l}\text { Weakness scores selected for } \\
\text { lesion volume comparison }\end{array}$ & Number & $\begin{array}{l}\text { Left side } \\
\text { lesion } \\
\text { volume } \\
\text { in } c c\end{array}$ & $95 \% C I$ \\
\hline $\begin{array}{l}\text { Face-shoulder-hand-hip-foot } \\
\text { Face-hand-foot only } \\
\text { Hand only } \\
\text { Hand or shoulder spared } \\
\text { Hand and shoulder spared }\end{array}$ & $\begin{array}{r}123 \\
77 \\
109 \\
230 \\
11\end{array}$ & $\begin{array}{l}49 \cdot 04 \\
57 \cdot 85 \\
50 \cdot 95 \\
63 \cdot 56 \\
23 \cdot 84\end{array}$ & $\begin{array}{l}39-58 \\
44-73 \\
44-61 \\
48-69 \\
11-34\end{array}$ \\
\hline
\end{tabular}

pared with weakness of both limbs and face. Major differences in lesion sizes were also found where the weakness was confined to the arm and where no weakness was found in either shoulder or hand. Table 2 shows the findings for left-sided infarcts. Essentially the same data was obtained for right-sided infarcts.

The low frequency of syndromes of incomplete hemiparesis or monoparesis frustrated attempts to correlate a specific syndrome with a specific brain location. An attempt was made to investigate the relationship further by grouping cases according to whether the lesion lay in the low, middle or high Rolandic region. For the left sided infarcts, 40 cases satisfied these criteria (table 3 ). The lesions varied widely in size but most were in the lower and middle third of the Rolandic region. Among them, 13 had no syndrome of weakness. Six of the cases had a lesion which crossed the Rolandic region in its lower third, while five were in the middle third. The face and shoulder were affected alone in two cases, both in the lower third of the Rolandic region. One case with a small mid-Rolandic infarct had weakness of the face, shoulder and hand while another in the same region affected the shoulder, thigh and ankle, sparing the face and hand. The thigh and ankle were affected in isolation in a single case whose infarct lay in the upper third of the Rolandic region. In seven cases the weakness of the face, shoulder and hand were more severe than the thigh and ankle. Hemiparesis affecting the face and both ipsilateral limbs to the same degree was also seen in eight cases, whose small lesion size and topographic distribution were no different from that seen for the incomplete syndromes of hemiparesis.

For the right sided infarcts, 41 cases satisfied these criteria. From the lower through the middle to the upper third of the Rolandic region, small and large infarcts appeared to have similar syndromes. The hint of a homunculus (face below, legs above) which might have been gleaned from the left hemispheral cases was not evident for infarcts on the right. In 4 cases, the face, shoulder and hand were affected, with sparing of the leg. In 15 cases, the face, shoulder and hand were more severely affected, than the leg. The face and both limbs were affected to the same degree in ten others. The face and shoulder was affected alone in one case, and the face and hand in another, both in the midRolandic region. Four had no syndrome of weakness.

Table 3 Frequency of weakness syndrome in left vs right hemispheral infarction

\begin{tabular}{lrl}
\hline & Left & Right \\
\hline Weakness syndrome & 40 & 41 \\
Face = Shoulder = Hand = Thigh = Ankle & 8 & 10 \\
Face = Shoulder = Hand $>$ Thigh = Ankle & 7 & 15 \\
Face = Shoulder = Hand & 1 & 4 \\
Face = Shoulder & 2 & 1 \\
Face = Hand & 0 & 1 \\
Shoulder = Thigh = Ankle & 1 & 0 \\
Thigh = Ankle & 1 & 0 \\
No weakness & 13 & 4 \\
Untestable & 7 & 6 \\
\hline
\end{tabular}


Follow up examination data at three and six months and one and two years, where available, failed to explain the discrepancies of the early examinations and also gave no indication of a reliable syndrome correlated either with lesion location or size.

\section{Discussion}

Our study showed a clear correlation between lesion volume on each side and all formulae of hemiparesis, corroborating the utility of the clinical scales in use. ${ }^{5-10}$ Furthermore, almost any measure of weakness (hand alone, arm, or face-hand-foot, or complete estimates of hemiparesis) seems enough to make a rough estimate of lesion size on a crude scale of small-medium-large. That the lesion size for a complete syndrome of hemiparesis (faceshoulder-hand-hip-foot) was roughly the same size as that for the arm and for the hand suggest that the hand and arm are so well represented that it is difficult to escape their involvement in cortical infarction.

Artifact seems an unlikely explanation for the range of findings in this large data set. The data collection methods had been validated. ${ }^{91617}$ The majority of lesions lay in the lower or middle third of the Rolandic region where the axis of the CT scan passes close to the Sylvian fissure, making errors in plotting the lesion unlikely. The asymmetry in findings on CT scan might be explained by the right Rolandic fissure normally being slightly forward of that of the left. ${ }^{18}$ Hypodense lesions on CT scan have been reported in the time frame applicable to our scans, from as early as 12 hours after onset of stroke to a peak by $72-96$ hours. ${ }^{19} 20$ By confining the analysis to those with a stable clinical course and with a superficial convexity infarction we minimised any role of "diaschesis" and of any important change in lesion size. ${ }^{21}$

Even with its large size, our study could be ignored by assuming that those with a severe hemiparesis and a small lesion on the initial CT would have shown a large one on a subsequent scan. This explanation, however, could not apply for the similar number showing a minor syndrome and a large lesion, nor for those that we and others ${ }^{22}$ found with no motor syndrome, despite an infarct straddling the Rolandic region. Arguably, MRI scanning or necropsy data might revise our findings, but it is unlikely that data from a series of this size will be mounted soon, nor are they certain to show any major differences.

The disturbing variation in lesion topography for a given formula of weakness make it uncertain as to which measure should be used to evaluate a worsening and lays a heavy burden on scales that use only one limb (usually the arm) for the evaluation. Our data also leave unresolved the question of whether worsening is best measured by subsequent involvement of parts initially spared (qualitative worsening) or by intensification of weakness in parts originally affected (quantitative worsening). Since recent clinical trials have shown rather modest changes in overall clini- cal scores in response to treatment, ${ }^{12}$ it is possible that the clinical assessment methods are not sensitive enough to show the range of treatment effects.

The variation in our data raises another, broader, concern about the reliability of a tight correlation between clinical function and circumscribed lesions. For syndromes of weakness after infarction, the data base of clinical correlations is a bit thin, with too much variation to provide robust support for a reliable homunculus formula. The classical necropsy-based literature is made up of single case reports, often from a single examination and necropsy carried out much later, ${ }^{23}$ and is too scant to test the range of syndromes even from Rolandic lesions. Work relying on angiographic occlusion alone or radionuclide brain scanning suffers from the uncertainties of the underlying infarct anatomy. From reports using brain imaging, we found no previous series of our size and few of any size adhering to a uniform protocol for clinica: and radiographic correlations. ${ }^{24}$ The largest series with CT scans we have found featured 48 patients with left hemispheral infarction studied by CT scan at five months, only 11 of whom had infarction involving the Rolandic convexity. ${ }^{22}$ Strength of the upper limb was studied using a composite score created for a variety of muscle groups from the shoulder through the fingers. Considerable variation occurred including some whose motor function was spared, the latter attributed to a "redundancy of representation of individual movements in the motor cortex," claimed earlier by Penfield and Boldrey. ${ }^{25}$

Functional studies using direct or indirect stimulation, measurements of blood flow or metabolic changes might help clarify the function of normal subjects but do not necessarily reflect syndromes after lesions. They form an even smaller data set. Yet even in these studies, remarkable inconsistency has been found in functional response from stimulation or activation of a given focus. Electrical stimulation of the brain surface, a major source of the homunculus metaphor in the 1930s, showed an orderly arrangement of face, arm, and leg but a great variety in the convexity sites which elicited the movements of the major body parts from patient to patient. ${ }^{325}$ Movement of the hand or foot occurred from low Rolandic stimulation in some cases, giving rise to speculations of a "second motor area", a thesis required to maintain the original one of a homunculus, yet the authors also noted that "...there is considerable variation from patient to patient in the position of the leg-arm boundary in the Rolandic areas...". ${ }^{26}$ Sensory evoked potentials mapping the cranial convexity showed spatially separate sites of response for the thumb, fifth finger, wrist, mid-arm and shoulder, ${ }^{27}$ and implanted subdural electrodes showed the fingers and arm movements occurring higher over the convexity than those for the head and mouth. ${ }^{28}$ Magnetic stimulation, however, has failed to show an orderly response, leading authors to question 
the adequacy of the homunculus model in humans. ${ }^{29}$ Regional cerebral blood flow studies have shown that hand movements activate large areas from the mid-Rolandic region well back into the parietal lobe and along a large vertical band. ${ }^{30}$

Animal studies, while providing better evidence for the homunculus thesis, are also too small a data set to address the range of correlations for a syndrome or a lesion. Judging from the larger size of brain lesions needed to recreate some syndromes seen in animals, ${ }^{31}$ it may be speculated that humans also have a different level of motor organisation than primates. Recent animal studies have shown that the Rolandic region has little of its space devoted to pure power; instead, highly organised patterns of movements associated with activation of single cells has moved the research field away from simplistic homunculus notions of sensorimotor organization. ${ }^{32}{ }^{33}$ If applicable to humans, these findings may mean that clinicians have placed the wrong emphasis on assessment of simple power as a guide to lesion site and size. To approximate the animal studies and determine how they relate to the clinical syndromes in brain-damaged humans, different strategies of clinical studies might be necessary, emphasising newly-devised testing of dyspraxias. Such testing, while possibly helpful in exploring the homunculus thesis, might be so elaborate that they could defeat the purposes of the acute rating scales useful for clinical trials.

These observations are not intended to impugn insights into motor organisation from primate models or studies in intact humans. ${ }^{3435}$ Whether an homunculus organisation exists in normal subjects is a separate issue from the predictable clinical response of the human cerebrum to a focal lesion. For clinical trials in patients before the development of the imaged brain lesion, our evidence suggests that the acute syndrome does not reliably predict the findings on CT to make either the syndrome or the scan a reliable estimate of the developing site or severity of the lesions in acute ischaemic stroke. Unless the drug effects are striking or the sample sizes are quite large, the scales in use could be an obstacle to progress. Their refinement may be necessary to achieve a better match of clinical score with lesion size and location and improve our insights into the response of the human brain to focal infarction and therapy.

Supported by contracts NO1-NS-2302, NO1-NS-2-2398, NO1-NS-2-2399, and NO1-NS-6-2305 from the National Institute of Neurological Disorders and Stroke, and by a gift from the Van Ingen Foundation.

1 Horsley V, Schaefer EA. A record of experiments upon the functions of the cerebral cortex. Phil Trans Roy Soc London 1888;B179:1-45.

2 Lloyd JH, Deaver JB. A case of focal epilepsy successfully treated by trephining and excision of motor centers. Am $\mathcal{F}$ Med Sci 1888;96:477-87.

3 Penfield W, Rasmussen T. The cerebral cortex of man. New York, Hafner, 1968, fig 72 .

4 Freund H-J. Abnormalities of motor behavior after cortical lesions in humans. In: Brookhart JM, Mountcastle VB, eds, Handbook of physiology, sect 1: Neurophysiology, Vol II: motor control, pt 2. Bethesda: American Physiological II: motor control, pt 2. Bet
5 Mathew NT, Meyer JS, Rivera VM, Charney JZ, Hartmann A. Double-blind evaluation of glycerol therapy in acute cerebral infarction. Lancet 1972;2:1327-9.

6 Orgogozo JM, Capildeo R, Anagnostou CN, et al. Mise au point d'un score neurologique pour l'evaluation clinique point d'un score neurologique pour l'evaluation cliniqu
des infarctus sylviens. Presse Med 1983;12:3039-44.

7 Cote R, Hachinski VC, Shurvell BL, Norris JW, Wolfson C. The Canadian Neurological Scale: a preliminary study in acute stroke. Stroke 1986;17:731-7.

8 Adams RJ, Meador KJ, Sethi KD, Grotta JC, Thomson DS. Graded neurological scale for use in acute hemispheric stroke treatment protocols. Stroke 1987;18: 665-9.

9 Foulkes MA, Wolf PA, Price TR, Mohr JP, Hier DB. The Stroke Data Bank: Design, methods, and baseline characteristics. Stroke 1988;19:547-54.

10 Brott T, Adams HP, Olinger CP, et al. Measurements of acute cerebral infarction: a clinical examination scale. Stroke 1989;20:864-70.

11 Potvin AR, Tourtellotte WW. Quantitative examination of neurologic function. Boca Raton: CRC Press, 1985:73.

12 The American Nimodipine Study Group. Nimodipine in acute ischemic stroke. Stroke 1992;23:1-5.

13 Polis AT, Foulkes MA, Mohr JP, Hier DB, Price TR, Wolf PA. Representing computerized tomographic scans using the GMAP procedure in SAS/GRAPH. Proc SAS Users Group Int Conference 1989;14:1162-5.

14 Damasio H: Vascular territories defined by computed tomography. In: Wood JH, ed. Cerebral Blood Flow. New York: McGraw-Hill, 1987.

15 Chodosh EH, Foulkes MA, Kase CS, et al. Silent stroke in the NINCDS Stroke Data Bank. Neurology 1988;38: 1674-8.

16 Shinar D, Gross CR, Mohr JP, et al Inter-observer variability in the assessment of neurologic history and examination in the Stroke Data Bank. Arch Neurol ination in the

17 Shinar D, Gross CR, Hier DB, et al Interobserver reliability in the interpretation of computed tomographic bility in the interpretation of computed tomograph
scans of stroke patients. Arch Neurol 1987;44:149-55.

18 LeMay M. CT changes in dementing diseases: a review. Am $\mathcal{F}$ Roentgenol 1986;147:963-75.

19 Mohr JP, Biller J, Hilal SK, et al. MR vs CT Imaging in Acute Stroke. Stroke 1992;23:142.

20 Brott T, Marler JR, Olinger CP, et al. Measurements of acute cerebral infarction: lesion size by computed tomography. Stroke 1989;20:871-5.

21 Wang AM, Lin JCT, Rumbaugh CL. What is expected of CT in the evaluation of stroke? Neuroradiol 1988;30: 54-8.

22 Knopman DS, Rubens AB. The validity of computed tomographic scan findings for the location of cerebral functions. Arch Neurol 1986;43:328-32.

23 Henschen SE. Klinische und Anatomische Beitrage zur Pathologie des Gehirns. Nordiska Bokhandeln: Stockholm, 1920

24 Lundgren J. Site of brain lesion and functional capacity in rehabilitated hemiplegics. Scand $\mathcal{f}$ Rehabil Med 1982;14:141-3.

25 Penfield W, Boldrey E. Somatic motor and sensory representation in the cerebral cortex of man as studied by electrical stimulation. Brain 1937;60:389-443.

26 Woolsey CN, Erickson TC, Gilson WE. Localization in somatic sensory and motor areas of human cerebral cortex as determined by direct recording of evoked potentials and electrical stimulation. $\mathcal{F}$ Neurosurg potentials and $1979 ; 51: 476-506$.

27 Cohen LG, Wang J, Salu $Y$, Hallett M. Physiological and anatomical correlations in noninvasive mapping if somatosensory cortex in humans. Neurology 1988;38(Suppl 1):387.

28 Neshige R, Lueders H, Friedman L, Shibasaki H Recording of movement-related potentials from the human cortex. Ann Neurol 1988;24:439-45.

29 Amassian VE, Cracco RQ, Maccabee PJ, Cracco JB. Is the classical motor homunculus representation correct? Neurology 1992;42(suppl 3):216.

30 Colebatch JG, Deiber MP, Passingham RE, Friston KJ Frackowiak RS. Regional cerebral blood flow during voluntary arm and hand movements in human subjects. f Neurophysiol 1991;65:1392-401.

31 Mori E, Yamadori A. Rejection behavior: a human homologue of the abnormal behavior of Denny-Brown and Chambers' monkey with bilateral parietal ablation. I Neurol Neurosurg Psychiatry 1989;52:1260-6.

32 Gentilucci M, Fogassi L, Luppino G, Matelli M, Camarda R, Rizzolatti G. Functional organization of inferior area 6 in the macaque monkey. I. Somatotopy inferior area 6 in the macaque monkey. I. Somatotopy and the control of

33 Rizzolatti G, Camarda R, Fogassi L, Gentilucci $M$, Luppino $G$, Matelli $M$. Functional organization of inferior area 6 in the macaque monkey. II. Area F5 and the control of distal movements. Exp Brain Res 1988;71: 491-507.

34 Phillips CG: Changing concepts of the precentral motor area. In: Eccles JC, ed. Brain and Conscious Experience. Springer Verlag: New York, 1966.

35 Evarts EV. Role of motor cortex in voluntary movements in primates. In: Brookhart JM, Mountcastle VB, eds. Handbook of physiology, sect 1: Neurophysiology, Vol II: Motor control, pt 2. Bethesda: American Physiological Society, 1981, 1083-1120. 